\title{
The Role of Perceived Parental Knowledge on Emerging Adults' Risk Behaviors
}

Laura M. Padilla-Walker

Brigham Young University - Provo

Larry J. Nelson

Brigham Young University - Provo, larry_nelson@byu.edu

Stephanie D. Madsen

McDaniel College

Carolyn McNamara Barry

Loyola College in Maryland

Follow this and additional works at: https://scholarsarchive.byu.edu/facpub

Part of the Other Social and Behavioral Sciences Commons

\section{Original Publication Citation}

Padilla-Walker, L. M., Nelson, L. J., Madsen, S., \& Barry, C. M. (2008). The role of perceived parental knowledge on emerging adults' risk behaviors. Journal of Youth and Adolescence, 37, 847-859.

\section{BYU ScholarsArchive Citation}

Padilla-Walker, Laura M.; Nelson, Larry J.; Madsen, Stephanie D.; and Barry, Carolyn McNamara, "The Role of Perceived Parental Knowledge on Emerging Adults' Risk Behaviors" (2008). Faculty Publications. 4678. https://scholarsarchive.byu.edu/facpub/4678 


\title{
The Role of Perceived Parental Knowledge on Emerging Adults' Risk Behaviors
}

\author{
Laura M. Padilla-Walker · Larry J. Nelson • \\ Stephanie D. Madsen · Carolyn McNamara Barry
}

Received: 18 October 2007/Accepted: 20 December 2007/Published online: 2 February 2008

(C) Springer Science+Business Media, LLC 2008

\begin{abstract}
The purpose of this study was to gain a clearer understanding of the relation between parents' knowledge of their emerging-adult children and emerging adults' risk behaviors. Participants included 200 undergraduate students between the ages of 18 and 25 (121 women, 78 men; $\left.M_{\text {age }}=19.59, S D=1.62\right)$ and both of their parents. Results revealed that knowledge of the emerging-adult child's activities varied as a function of parent- and childreports, and that child outcomes associated with parental knowledge were generally positive, including less drinking, drug use, and risky sexual behavior (although this varied as a function of reporter). The links between maternal knowledge and lower drug and alcohol use were particularly strong in the presence of maternal closeness. Implications for understanding the parent-child relationship during the transition to adulthood were discussed.
\end{abstract}

Keywords Parental knowledge - Emerging adulthood · Parent-child relationship $\cdot$ Risk behaviors

L. M. Padilla-Walker $(\square)$

Brigham Young University, 2097 JFSB, School of Family Life, Provo, UT 84602, USA

e-mail: laura_walker@byu.edu

L. J. Nelson

Brigham Young University, 2091 JFSB, School of Family Life, Provo, UT 84602, USA

S. D. Madsen

McDaniel College, Westminster, MD, USA

C. M. Barry

Loyola College in Maryland, Baltimore, MD, USA

\section{Introduction}

Ample research has focused on the role of parents as socialization agents in the lives of children and adolescents, and the role of parental monitoring in particular (see Edwards and Liu 2002; Maccoby 1992; Steinberg 2001; Steinberg and Silk 2002). However, the influence and involvement of parents does not cease when children leave the family home (Zarit and Eggebeen 2002). Indeed, research on parent-child relationships in adulthood suggests that relationships between parents and their adult children continue to be important, especially during times of transition (Bartle-Harin et al. 2002; O'Connor et al. 1996). Emerging adulthood has been characterized as one such time of transition. Therefore, the purpose of this study was to examine the relations between parental knowledge (or monitoring) and parental closeness, and emerging adults' risk behaviors (i.e., drug use, alcohol use, number of sexual partners) and to explore how these relations differed as a function of the gender of the child and the gender of each parent.

\section{Theoretical Framework}

Research has examined parental involvement with adult children (typically focusing on middle-aged children), but there has been comparatively less research examining the parent-child relationship during the transition to adulthood. Although this developmental period has been referred to using various terms in the past (see Côté 2000; Keniston 1971), most recently scholars have referred to this period as "emerging adulthood" (Arnett 2000). Given the lack of theory and limited research regarding parent-child relationships in emerging 
adulthood, we drew from work examining parent-child relationships both in earlier (adolescence) and subsequent (adulthood) periods of development. We drew on research by Darling and Steinberg (1993), who provide a theoretical framework for understanding the context of parenting styles. A central tenet of their theory is that the emotional climate created by the parents provides the milieu in which children interpret parental behaviors. For example, parental monitoring, or a parent's knowledge of his or her child's activities, is considered to be an important aspect of parenting during childhood and adolescence (Steinberg 2001). Parental monitoring within a climate lacking in warmth may be perceived by the adolescent as controlling, while the same parental behavior within a warm environment may be perceived as legitimate concern.

This theoretical framework may have important utility in helping to understand the parent-child relationship in emerging adulthood as well. Emerging adulthood has been described as a time of transition, wherein young people strive for relational maturity and want to become independent, self-reliant individuals while simultaneously establishing an equal relationship with parents (e.g., Arnett 2006, 2007; Badger et al. 2006; Nelson and Barry 2005). The balance of autonomy and relatedness in parent-child relationships necessarily adjusts to transitions inherent in emerging adulthood such as leaving home or entering college/university (O'Connor et al. 1996). Most, but not all, emerging adults report positive changes in relationship quality with their parents, including increases in open communication and greater appreciation/respect for parents across such transitions (Lefkowitz 2005; Strom and Strom 2005). Given this variability, the closeness of the relationship with parents may be a critical determining factor in how parental behaviors such as monitoring are perceived. Indeed, understanding the roles of monitoring and closeness appears to be particularly important in relation to risk behaviors in emerging adulthood. Parents report that complying with societal norms (e.g., refraining from binge drinking or drug use) is essential in the process of becoming an adult (Nelson et al., in press); yet, during emerging adulthood there is a heightened participation in risk behaviors (Arnett 2005, 2006; Schulenberg and Zarrett 2006). Thus, parents may be especially concerned with and vigilant of their children's participation in risk behaviors during emerging adulthood. It is possible that parental closeness, therefore, may act as a moderating variable between parental knowledge and child outcomes, in that, parental monitoring may be differentially related to emerging adults' risk behaviors at different levels of parental closeness.
Empirical Foundation

Considerable empirical evidence supports the linkages between parental monitoring, parental closeness, and child risk behaviors during adolescence. To reiterate, the study of parental knowledge of children's activities is commonly referred to as "parental monitoring." However, recent reconceptualizations suggest that because most measures of parental monitoring capture what parents know rather than what they actively do to obtain this information, it is more accurate to refer to this concept as parental knowledge (Crouter and Head 2002; Kerr and Stattin 2000). A few studies have asked both parents and adolescents about how much the parent knows and found only modest correlations between the family members' reports (e.g., Pettit et al. 2001; Stattin and Kerr 2000). These findings suggest a lack of certainty or accuracy on the part of both parent and child regarding how much parents know about the child's activities. In other words, researchers may often be tapping into what individuals (i.e., parents and adolescents) think they know rather than what they actually know. Thus, in the current study, parental monitoring was defined as perceived parental knowledge about where their children are, what they are doing, and with whom they spend time. Furthermore, this definition applies to both parent and child perceptions of parental knowledge because both parent and child have only rough estimations of the other's thoughts (i.e., knowledge) and behaviors.

During childhood and adolescence, parental knowledge is associated with a number of positive outcomes. For example, research suggests that parental knowledge has been linked to lower levels of adolescent externalizing behaviors, such as substance use (Pettit et al. 2001; Tragesser et al. 2007), delinquency (Barnes et al. 2006), and sexual activity (Longmore et al. 2001); and lower levels of internalizing behaviors, such as depressed mood and low self-esteem (Kerr and Stattin 2000; Stattin and Kerr 2000). Although parental knowledge often is conceptualized as a form of parental control, recent reconceptualizations suggest that how much parents know about their child is determined more strongly by the child's willingness to share information with parents than it is with parental solicitation or control. For example, Kerr and Stattin (2000) found that although parental knowledge (via both child report and parent report) was related to a number of positive outcomes during adolescence, the strength of the relation between knowledge and outcomes was reduced (but was still significant) when child disclosure was added to the model. This research highlights the importance of the quality of the parent-child relationship and is consistent with research suggesting that a close parent-child relationship fosters parental knowledge and helps to promote 
positive outcomes in youth (Dishion and McMahon 1998). From this and other research, and in support of Darling and Steinberg's (1993) model, we can conclude that both parental knowledge and parental closeness are important correlates of positive outcomes during adolescence (see Steinberg 2001 for a review), and thus we have included both constructs in the present study.

Whereas we can be relatively confident that parental knowledge and a close parent-child relationship are both conducive to positive development during adolescence, we know much less about the role of these two aspects of parenting once children begin the transition to adulthood. Although recent studies support the importance of a high quality parent-child relationship during emerging adulthood (Barry et al., in press; Kenny and Sirin 2006) there is no relevant literature on parental knowledge during emerging adulthood. One possibility is that parental knowledge no longer is related to positive outcomes at this age, as it is the expectation of many emerging adults that parental knowledge and surveillance will decrease significantly upon their leaving the home. Indeed, research suggests that parental knowledge decreases as children become more involved in activities outside the home during adolescence (Crouter et al. 1999; Feiring and Lewis 1993). Alternatively, it is possible that a close parent-child relationship during emerging adulthood may result in continued high levels of parental knowledge (due primarily to high child disclosure). If this were the case, then it is possible that parental knowledge may continue to be related to positive outcomes during emerging adulthood.

It is also possible that once children begin the transition to adulthood, they may interpret a parent's desire for knowledge differently than when they were adolescents. Research has found that intrusive and overprotective parenting, for example, is related to depression and diminished social competence during adolescence (Allen and McElhaney 2000; Barber et al. 1994; Steinberg 1990). Research also has found that adolescents' feelings of being controlled are related to higher depressed mood and lower positive adjustment (Kerr and Stattin 2000). Thus, as children enter emerging adulthood, the interplay between children's desire for autonomy and parents' continued desire to have knowledge of their children's activities may be a source of tension for parents and their emerging-adult children (Aquilino 2006). Given that emerging adults are striving to develop a relationship as equals with their parents (e.g., Nelson and Barry 2005), emerging adulthood may be a time period in which parental knowledge that is interpreted as intrusive or controlling may be particularly likely to be related to negative behavioral outcomes.

The current study sought to gain a clearer understanding of the relation between parental knowledge and emerging adults' risk behaviors (i.e., drug use, alcohol use, number of sexual partners). These outcomes were selected based on their prevalence during this time period (see Arnett 2000, 2005) and the negative consequences associated with these behaviors. While it may be argued that sexual relations are a normative form of exploration during this age period (see Arnett 2006), the number of sexual partners has been found to be a risk factor in development (e.g., Guo et al. 2002; Santelli et al. 1998). Taken together, the current study sought to gain a clearer understanding of the relation of perceived parental knowledge of emerging adults' risk behaviors by specifically examining (a) the relation between parent and emerging-adult reports of parental knowledge, (b) whether parental knowledge was related to emerging-adult outcomes over and above that accounted for by the closeness of the parent-child relationship, (c) the interaction between parental knowledge and parental closeness to assess whether parental closeness moderated the relation between parental knowledge and child outcomes, and (d) how relations differed as a function of the gender of the child and the gender of the parent.

\section{Hypotheses}

First, based on existing research on adolescents (Pettit et al. 2001; Stattin and Kerr 2000), we examined the relation between parent and emerging-adult reports of parental knowledge, and expected that they would be related, albeit weakly, to one another. Second, we examined whether parental knowledge was related to emerging-adult outcomes over and above the variance accounted for by the closeness of the parent-child relationship. Although parental closeness and parental knowledge are related closely, we expected parental knowledge to be related uniquely to positive outcomes during emerging adulthood even after closeness was taken into account (Kerr and Stattin 2000). Third, we explored the interaction between parental knowledge and parental closeness to assess whether parental closeness moderated the relation between parental knowledge and child outcomes. It is possible that parental knowledge in the context of a close parent-child relationship is interpreted more positively than parental knowledge in the context of a distant parent-child relationship, where it may be interpreted as intrusive. Thus, we expected parental knowledge to be related more strongly to lower levels of risk behaviors in the context of a close parent-child relationship. We also examined these relations separately for parent- and child-reported parental knowledge. Despite low correlations between parent- and childreported knowledge, research on adolescence suggests similar patterns across parent and child reports (Kerr and Stattin 2000). However, it is possible that geographical distance during emerging adulthood might result in larger 
discrepancies or different patterns of results as a function of parent- and child-reported parenting behaviors (e.g., Barry et al. 2007).

In addition, we expected parental knowledge (and its relations to outcome variables) to differ as a function of the gender of the parent and the gender of the child. Mothers are generally closer to their children and know more about their children's activities than do fathers (Crouter et al. 1999). Thus, it is possible that parental knowledge is related differentially to child outcomes as a function of the gender of the parent, with more outcomes expected to be tied to perceived maternal knowledge than paternal knowledge. Although consistent differences in parental knowledge have not been found as a function of the gender of the child, some studies have found that mothers have greater knowledge of their daughters while fathers have greater knowledge of their sons (Crouter et al. 1999). Thus, we also examined differences in parental knowledge as a function of gender of the child.

\section{Methods}

\section{Participants}

Participants for this study were drawn from a study of emerging adults and their parents entitled "Project READY" (Researching Emerging Adults' Developmental Years). This project is an ongoing, collaborative, multi-site study that is being conducted by a consortium of developmental and family scholars, and data used in the current study were collected during the 2006-2007 academic school year.

The sample selected for the current study $\left(M_{\mathrm{age}}=\right.$ $19.59, \quad S D=1.62, \quad$ range $=18-25)$ consisted of 200 undergraduate students (121 women, 78 men) and their fathers and mothers $\left(M_{\text {age }}\right.$ Father $=50.64, S D=5.21$, range $=36-72 ; \quad M_{\text {age }} \quad$ Mother $=48.94, \quad S D=4.46$, range $=38-64)$. These families were chosen for the current study (from a larger sample of approximately 400 emerging adults with at least one participating parent) so comparisons on parental knowledge could be made across children, mothers, and fathers from the same family. Participants were recruited from four college sites across the United States (56\% from two mid-Atlantic colleges, $27 \%$ from a Midwestern university, and $17 \%$ from a West Coast university). Response rates varied by site (ranging from $50 \%$ to $75 \%$ ), with an overall response rate of approximately $63 \%$. In terms of year in school, $38 \%$ of emerging adults were in their first year, $25 \%$ second year, $19 \%$ third year, $13 \%$ fourth year, and $7 \%$ fifth year. The majority of emerging adults were European American (90\% European American, 3\% African American, 3\% Asian American, 1\%
Latino American, and $3 \%$ other). Ninety percent of emerging adults reported living outside of their parents' home in an apartment, house, or dormitory. Ten percent reported living in their parents' home. Seventy percent of fathers and $66 \%$ of mothers reported having a bachelor's degree or more, $35 \%$ of parents reported making between $\$ 50,000$ and $\$ 75,000$ per year, with $59 \%$ reporting a combined income of over $\$ 100,000$.

\section{Procedures}

Participants completed the Project READY questionnaire via the Internet (see http://www.projectready.net). The use of an online data collection protocol facilitated unified data collection across multiple university sites and allowed for the survey to be administered to emerging adults and their parents who were living in separate locations throughout the country. Participants were recruited through faculty's announcement of the study in undergraduate and graduate courses. Undergraduate courses were primarily Introduction to Psychology courses or large general education courses of the like in an attempt to access a broad range of students. Professors at the various universities were provided with a handout to give to their students that had a brief explanation of the study and directions for accessing the online survey. Interested students then accessed the study website with a location-specific recruitment code. Informed consent was obtained online, and only after consent was given could the participants begin the questionnaires. Each participant was asked to complete a survey battery of 448 items. Sections of the survey addressed topic areas such as background information, family-of-origin experiences, self-perceptions, personality traits, values, risk behaviors, dating behaviors, prosocial behaviors, and religiosity. Participants were offered course credit or extra credit for their own participation, and were offered small monetary compensation (i.e., \$10-20 gift certificates) for their parents' participation.

After participants completed the personal information, they had the option to send an email invitation to their parents to participate in the study. The email invitation included an assigned password and a link to the parents' version of the questionnaire. The parents were directed to click on the link and enter the password. Once the password was entered, an informed consent form appeared and parents then followed the same protocol as their children. If parents did not have e-mail addresses, mailing addresses were obtained and questionnaires were mailed to them with self-addressed, pre-paid envelops for them to mail back completed surveys. Parents completed a shorter battery of 280 items similar to the ones their children completed, asking them to respond from a parental point of view. 


\section{Measures}

For the current study we examined emerging adults' and their parents' reports of parental knowledge. We also examined emerging adults' reports of paternal and maternal closeness, and emerging adults' reports of their own drinking, drug use, and number of sexual partners.

\section{Parental Knowledge}

Parental knowledge was measured using Barber's Regulation Scale (Barber et al. 1994), which has been used in past research and has demonstrated adequate reliability and validity (e.g., Bean et al. 2006). Both emerging adults and their parents answered eight questions assessing parental knowledge. Sample items include, "Knows who my friends are (I am aware who his/her friends are)," and "Knows whether I use drugs (I am aware of whether he/she uses drugs)." Emerging adults answered these questions for both their father and mother, and parents answered these questions for their child. Items were rated on a three-point scale ranging from 1(doesn't know/don't know) to 3 (knows a lot/know a lot). Individual items were averaged, with higher scores representing greater parental knowledge. Cronbach's alphas for emerging adults' reports of paternal and maternal knowledge were .81 and .76 , respectively. Cronbach's alphas for fathers' and mothers' reports of their own knowledge of their child were .82 and .84 , respectively.

\section{Parental Closeness}

Parental closeness was measured using the Parent-Child Closeness Scale, which has demonstrated adequate reliability and validity in past studies (Buchanan et al. 1991). Emerging adults responded to nine items assessing paternal and maternal closeness (18 items total). Sample items include, "How openly do you talk with your (father/ mother)?," and "How well does your (father/mother) know what you are really like?" Items were rated on a 5-point scale ranging from 1 (not at all) to 5 (very). Individual items were averaged for fathers and mothers, with higher scores representing greater parental closeness. Cronbach's alphas for emerging adults' reports of paternal and maternal closeness were .92 and .88 , respectively.

\section{Drinking}

Emerging adults' drinking was measured using two items from the Add Health Questionnaire (http://www.cpc. unc.edu/addhealth/). Emerging adults were asked how many days in the past 12 months they drank alcohol and engaged in binge drinking (i.e., 4-5 drinks on one occasion). Participants rated these items on a 6-point Likerttype scale ranging from 0 (none) to 5 (almost every day). Because items were correlated $(r=.82, p<.001)$ responses were averaged, with higher scores indicating more frequent drinking behavior $(M=2.05, S D=1.26$, range $=0-5.00)$.

\section{Drug Use}

Emerging adults' drug use was measured using two items from the Add Health Questionnaire (http://www.cpc. unc.edu/addhealth/). Emerging adults were asked how many days in the past 12 months they used marijuana and used other illegal drugs (e.g., cocaine, heroin, crystal meth, and mushrooms). Participants rated these items on a 6-point Likert-type scale ranging from 0 (none) to 5 (almost every day). Because items were correlated $(r=.46, p<.001)$ responses were averaged, with higher scores indicating more frequent drug use $(M=.35$, $S D=.77$, range $=0-4.50)$.

\section{Number of Sexual Partners}

Emerging adults' sexual risk taking was measured using two items from the Add Health Questionnaire (http://www. cpc.unc.edu/addhealth/) assessing number of sexual partners. Emerging adults were asked how many sexual partners they had in the past 12 months, and how many sexual partners they had in their lifetime. Because items were correlated $(r=.78, p<.001)$ responses were averaged, with higher scores indicating a higher number of sexual partners $(M=1.94, S D=3.15$, range $=0-31)$.

\section{Results}

\section{Descriptive Statistics}

A number of bivariate correlations were conducted to determine whether study variables were related to continuous demographic variables (e.g., age, income). The only significant correlations were regarding age, with age of the emerging adult positively related to number of sexual partners $(r=.32, p<.001)$, and negatively related to parent-reported paternal $(r=-.21, p<.01)$ and maternal knowledge $(r=-.18, p<.01)$. Thus, age was used as a control variable in the subsequent regression analyses. 
A number of univariate analyses of variance (ANOVAs) were conducted to determine whether study variables differed as a function of categorical demographic variables (e.g., gender, year in school, or ethnicity). Of the analyses conducted, only gender was related significantly to study variables. Namely, four of the five analyses conducted regarding gender were statistically significant. Young men $(M=.58, S D=1.08)$ reported higher drug use than did young women $(M=.20, S D=.42)$, $F(1,196)=12.06, p<.001 ;$ young men $(M=2.51$, $S D=4.03)$ reported more sexual partners than did young women $(M=1.57, \quad S D=2.23), \quad F(1, \quad 196)=4.35$, $p<.05$; and young women reported higher levels of maternal $(M=4.55, S D=.50)$ and paternal closeness $(M=4.23, S D=.67)$ than did young men $(M=3.62$, $S D=1.19$ for maternal; $M=3.77, S D=.87$ for paternal), $F(1,195)=56.36, p<.001$ for maternal closeness; $F(1,196)=17.56, p<.001$ for paternal closeness. Due to these gender differences, gender was used as a control variable in the regression analyses.

\section{Differences Between Child- and Parent-reported Parental Knowledge}

To determine differences between child-and parent-reported parental knowledge as a function of child gender, a $2 \times 2 \times 2$ mixed model ANOVA was conducted, with child gender (male versus female) as a between-group effect, and parent gender (father versus mother) and source (parent versus child) as within-group effects. Results revealed a main effect of child gender, $F(1,194)=15.15$, $p<.001$, with young women rating parental knowledge higher than did young men; parent gender, $F(1$, $194)=33.51, p<.001$, with mothers rating parental knowledge higher than did fathers; and source, $F(1$, $194)=21.63, p<.001$, with parents rating parental knowledge higher than did children (see Table 1). None of the interactions were statistically significant.

\section{Correlations Between Parental Knowledge, Parental Closeness, and Child Outcomes}

A number of correlations were conducted to determine whether parental knowledge and parental closeness were related to emerging adults' risk behaviors. Results presented in Table 2 show that child and parent reports of parental knowledge were correlated, as were parental knowledge and parental closeness (the latter correlation was significantly stronger for child-reported paternal knowledge than for parent-reported paternal knowledge). Child-reported paternal knowledge was related negatively
Table 1 Means and standard deviation of parental knowledge by respondent and gender

\begin{tabular}{lll}
\hline Respondent & Child gender & $M(S D)$ \\
\hline $\begin{array}{l}\text { Paternal knowledge } \\
\text { Child report }\end{array}$ & Male & \\
& Female & $2.18(.49)$ \\
& Total & $2.28(.42)$ \\
Father report & Male & $2.23(.45)$ \\
& Female & $2.30(.41)$ \\
& Total & $2.47(.39)$ \\
Maternal knowledge & & $2.40(.41)$ \\
Child report & Male & \\
& Female & $2.30(.44)$ \\
& Total & $2.47(.40)$ \\
Mother report & Male & $2.41(.43)$ \\
& Female & $2.37(.38)$ \\
& Total & $2.63(.39)$ \\
& & $2.52(.40)$ \\
\hline
\end{tabular}

Note. A 2 (child gender) $\times 2$ (parent gender) $\times 2$ (source) ANOVA revealed that young women rated parental knowledge higher than young men, mothers rated parental knowledge higher than did fathers, and parents rated parental knowledge higher than did children

to drug use and child-reported maternal knowledge was related negatively to drinking and drug use. Parentreported paternal knowledge was related negatively to drug use and parent-reported maternal knowledge was related negatively to drinking and drug use. Although correlational findings were relatively consistent across parent- and child-reports, given the possibility that patterns of results might differ by reporter, subsequent analyses were conducted separately for parent- and childreports of parental knowledge.

\section{Hierarchical Regression Analyses Predicting Emerging Adults' Risk Behaviors}

Because parental knowledge and parental closeness were so highly correlated ( $r$ 's ranged from .44 to .63), and to determine whether there was an interaction between these two aspects of parenting during emerging adulthood, we conducted a series of hierarchical regression analyses. The goal of these analyses was twofold: (1) to determine whether parental knowledge was related to outcomes over and above the variance accounted for by parental closeness, and (2) to determine whether parental closeness moderated the relation between parental knowledge and emergingadult outcomes.

For each regression analysis, the child's age and gender were entered as control variables in the first step, parental closeness was entered in the second step, parental knowledge was entered in the third step, and the interaction 
Table 2 Correlations between parental knowledge, parental closeness, and emerging adult outcomes

\begin{tabular}{|c|c|c|c|c|c|c|c|c|}
\hline & 1 & 2 & 3 & 4 & 5 & 6 & 7 & 8 \\
\hline 1. Paternal knowledge (CR) & - & & & & & & & \\
\hline 2. Paternal knowledge (PR) & $.27 * * *$ & - & & & & & & \\
\hline 3. Maternal knowledge (CR) & $.65^{* * * *}$ & $.21 * * *$ & - & & & & & \\
\hline 4. Maternal knowledge (PR) & $.31 * * *$ & $.43 * * *$ & $.53 * * *$ & - & & & & \\
\hline 5. Paternal closeness (CR) & $.62 * * *$ & $.27 * * *$ & $.32 * * *$ & $.23 * * *$ & - & & & \\
\hline 6. Maternal closeness (CR) & $.37 * * *$ & $.21 * * *$ & $.44 * * *$ & $.36 * * *$ & $.64 * * *$ & - & & \\
\hline 7. Drinking (CR) & -.08 & -.02 & $-.14 *$ & $-.14 *$ & .08 & .06 & - & \\
\hline 8. Drug use (CR) & $-.17 * *$ & $-.14 *$ & $-.08 *$ & $-.15^{*}$ & -.05 & -.03 & $.38 * * *$ & - \\
\hline 9. Sex (CR) & -.04 & -.08 & -.01 & $-.18 * *$ & .04 & .02 & $.23 * * *$ & $.18^{* *}$ \\
\hline
\end{tabular}

Note. $\mathrm{CR}=$ child report and $\mathrm{PR}=$ parent report

$* p<.05, * * p<.01, * * * p<.001$

between parental closeness and parental knowledge was entered in the fourth step. The scores on the predictors were centered prior to analyses to reduce collinearity formed by the interaction. To examine the interactions between the two variables, we calculated simple regression slopes for each predictor with values corresponding to one standard deviation above the mean and one standard deviation below the mean of parental closeness (Aiken and West 1991). No significant interactions were found as a function of child gender, so gender interactions were not presented.

\section{Child-report}

Emerging adults' self-reported drinking was the criterion variable in the first analyses presented in Table 3. At Step 1 , child age and gender were not related to drinking, $F(2$, $192)=.69$, ns. At Step 2, paternal and maternal closeness did not result in an increase in the proportion of variance accounted for, $F \Delta(2,190)=1.71$, ns. At Step 3, paternal and maternal knowledge produced a $5 \%$ increase in the proportion of variance accounted for, $F \Delta(2,188)=4.61$, $p<.01$, with maternal knowledge marginally and

Table 3 Hierarchical regression analyses predicting emerging adults' risk behaviors from parental closeness and child- and parent-reported parental knowledge

\begin{tabular}{|c|c|c|c|c|c|c|}
\hline \multirow[t]{2}{*}{ Variable entered } & \multicolumn{3}{|c|}{ Child-report } & \multicolumn{3}{|c|}{ Parent-report } \\
\hline & Drinking & Drug use & Sex & Drinking & Drug use & Sex \\
\hline \multicolumn{7}{|l|}{ Step 1} \\
\hline Child age & -.02 & -.07 & $.30 * * *$ & -.02 & -.07 & $.30 * * *$ \\
\hline Child gender & -.08 & $-.24 * * *$ & -.09 & -.08 & $-.24 * * *$ & -.09 \\
\hline$R^{2}$ change & .01 & $.06 * * *$ & $.11 * * *$ & .01 & $.06 * * *$ & $.11 * * *$ \\
\hline \multicolumn{7}{|l|}{ Step 2} \\
\hline Paternal closeness (A) & .08 & -.06 & .11 & .08 & -.06 & .11 \\
\hline Maternal closeness (a) & .08 & .15 & .03 & .08 & .15 & .03 \\
\hline$R^{2}$ change & .01 & .01 & .01 & .01 & .01 & .01 \\
\hline \multicolumn{7}{|l|}{ Step 3} \\
\hline Paternal knowledge (B) & -.14 & $-.34 * * *$ & $-.22 *$ & .04 & -.07 & .04 \\
\hline Maternal knowledge (b) & $-.16 \dagger$ & .10 & .09 & $-.18^{*}$ & -.10 & $-.17 *$ \\
\hline$R^{2}$ change & $.05 * *$ & .05 & $.02 *$ & $.03 *$ & .02 & $.03 *$ \\
\hline \multicolumn{7}{|l|}{ Step 4} \\
\hline $\mathrm{A} \times \mathrm{B}$ & -.05 & -.05 & -.01 & -.07 & .15 & -.02 \\
\hline $\mathrm{a} \times \mathrm{b}$ & -.11 & .07 & -.08 & $-.38 * * *$ & $-.32 * * *$ & $-.18^{*}$ \\
\hline$R^{2}$ change & .02 & .02 & .01 & $.10 * * *$ & $.09 * * *$ & .02 \\
\hline Model $R^{2}$ & $.09 *$ & $.14 * * *$ & $.15 * * *$ & $.15^{* * *}$ & $.17 * * *$ & $.17 * * *$ \\
\hline
\end{tabular}

Note. All beta weights are standardized

$\dagger p<.10, * p<.05, * * p<.01, * * * p<.001$ 
negatively related to drinking. At Step 4, the interaction did not significantly increase the proportion of variance accounted for, $F \Delta(2,186)=1.64$, ns., with an overall model $R^{2}=.09, F(8,186)=2.50, p<.05$.

Emerging adults' self-reported drug use was the criterion variable in the second analyses presented in Table 3. At Step 1 child gender was related negatively to drug use (young women had the higher coded value), $F(2$, $192)=6.54, p<.01$. At Step 2, paternal and maternal closeness did not result in an increase in the proportion of variance accounted for, $F \Delta(2,190)=1.24$, ns. At Step 3, paternal and maternal knowledge produced a $5 \%$ increase in the proportion of variance accounted for, $F \Delta(2$, $188)=4.99, p<.01$, with paternal knowledge negatively related to drug use. At Step 4, the interaction did not significantly increase the proportion of variance accounted for, $F \Delta(2,186)=.46$, ns., with an overall model $R^{2}=.14$, $F(8,186)=3.70, p<.001$.

Emerging adults' self-reported number of sexual partners was the criterion variable in the third analyses presented in Table 3. At Step 1 child age was related positively to sexual behavior, $F(2,192)=11.80, p<.001$. At Step 2, paternal and maternal closeness did not result in an increase in the proportion of variance accounted for, $F \Delta(2,190)=1.49$, ns. At Step 3, paternal and maternal knowledge resulted in a $2 \%$ increase in the proportion of variance accounted for, $F \Delta(2,188)=1.95, p<.05$, with paternal knowledge negatively related to number of sexual partners. At Step 4, the interaction did not significantly increase the proportion of variance accounted for, $F \Delta(2$, $186)=.75$, ns., with an overall model $R^{2}=.15, F(8$, 186) $=4.03, p=.001$.

\section{Parent-report}

Emerging adults' self-reported drinking was the criterion variable in the first analyses presented in Table 3. At Step 1 child age and gender were not significantly related to drinking, $F(2,194)=.78$, ns. At Step 2, paternal and maternal closeness did not result in an increase in the proportion of variance accounted for, $F \Delta(2,192)=1.54$, ns. At Step 3, paternal and maternal knowledge produced a $2 \%$ increase in the proportion of variance accounted for, $F \Delta(2,190)=2.46, p=.08$, with maternal knowledge negatively related to drinking. At Step 4, the interaction produced a $10 \%$ increase in the proportion of variance accounted for, $F \Delta(2,188)=10.64, p<.001$, with the interaction between maternal closeness and maternal knowledge negatively related to drinking, and an overall model $R^{2}=.15, F(8,188)=4.55, p<.001$. A graphic representation of this interaction is presented in Fig. 1. A test of the simple slopes indicated that maternal

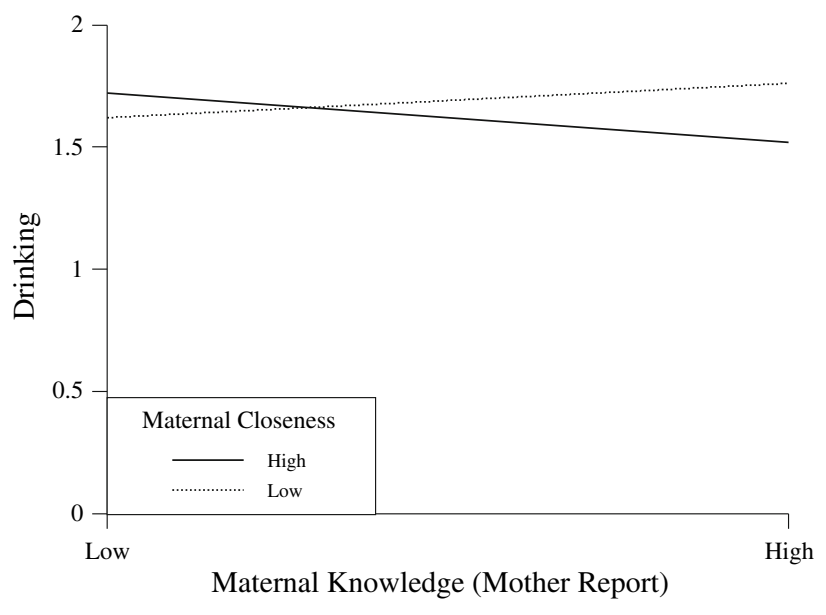

Fig. 1 Simple slopes of mother-reported maternal knowledge regressed on drinking at high and low values of maternal closeness

knowledge was related significantly to drinking at +1 standard deviation of maternal closeness, $\beta=-.21$, $t(193)=-3.28, p<.001$, but not at -1 standard deviation of maternal closeness. In other words, there was a significant negative relation between maternal knowledge and child-reported drinking behavior only when maternal closeness was high.

Emerging adults' self-reported drug use was the criterion variable in the second analyses presented in Table 3. At Step 1, child gender was related negatively to drug use (young women had the higher coded value), $F(1$, $194)=6.74, p<.001$. At Step 2, paternal and maternal closeness did not result in an increase in the proportion of variance accounted for, $F \Delta(2,192)=1.24$, ns. At Step 3, paternal and maternal knowledge did not result in an increase in the proportion of variance accounted for, $F \Delta(2$, $190)=1.73$, ns. At Step 4 , the interaction produced a $9 \%$ increase in the proportion of variance accounted for, $F \Delta(2$, $188)=9.70, \quad p<.001$, with the interaction between maternal closeness and maternal knowledge negatively related to drug use, and an overall model $R^{2}=.17, F(8$, $188)=5.66, p<.001$. A graphic representation of this interaction is presented in Fig. 2. A test of the simple slopes indicated that maternal knowledge was related significantly to drug use at +1 standard deviation of maternal closeness, $\beta=-.21, t(193)=-3.28, p<.001$, but not at -1 standard deviation of maternal closeness. In other words, there was a significant negative relation between maternal knowledge and child-reported drug use only when maternal closeness was high.

Emerging adults' self-reported sexual behavior was the criterion variable in the third analyses presented in Table 3. At Step 1, child age was related positively to sexual behavior, $F(1,194)=12.07, p<.001$. At Step 2, paternal and maternal closeness did not result in an increase in the 


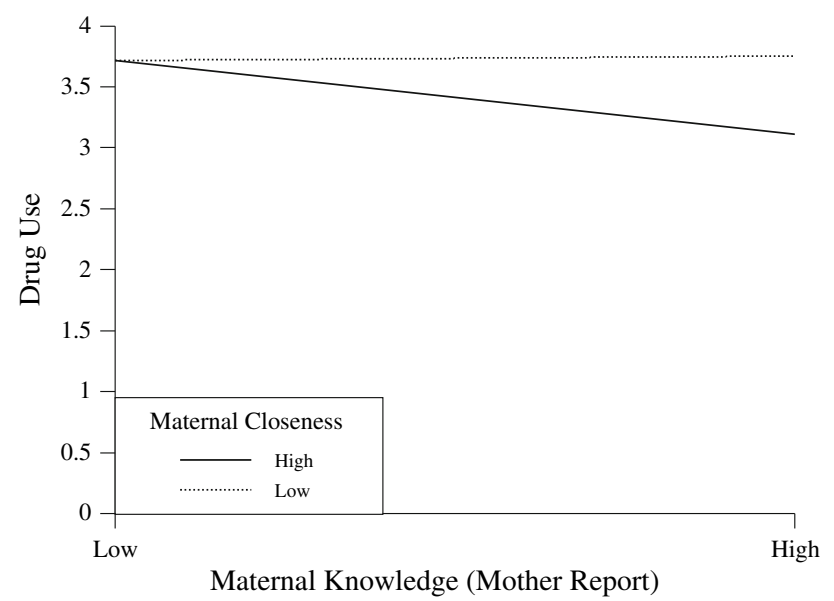

Fig. 2 Simple slopes of mother-reported maternal knowledge regressed on drug use at high and low values of maternal closeness

proportion of variance accounted for, $F \Delta(2,192)=1.46$, ns. At Step 3, paternal and maternal knowledge produced a $3 \%$ increase in the proportion of variance accounted for, $F \Delta(2,190)=2.37, p<.05$, with maternal knowledge negatively related to sexual behavior. At Step 4, the interaction did not result in an increase in the proportion of variance accounted for, $F \Delta(2,188)=2.30$, ns., with an overall model $R^{2}=.17, F(8,188)=4.67, p<.001$.

\section{Discussion}

The current study sought to gain a clearer understanding of the relation of perceived parental knowledge to emerging adults' risk behaviors (i.e., drug use, alcohol use, number of sexual partners) by specifically examining (a) the relation between parent and emerging-adult reports of parental knowledge, (b) whether parental knowledge was related to emerging-adult outcomes over and above that accounted for by the closeness of the parent-child relationship, (c) the interaction between parental knowledge and parental closeness to assess whether parental closeness moderated the relation between parental knowledge and child outcomes, and (d) how relations differed as a function of the gender of the child and the gender of the parent.

Results revealed several significant findings. Perceptions of parental knowledge were associated with child behaviors, but the pattern of relations differed between parentand child-reports of this knowledge. For child-reported parental knowledge, maternal knowledge negatively predicted drinking, albeit marginally, while paternal knowledge significantly and negatively predicted drug use and number of sexual partners. For parent-reported knowledge, maternal knowledge negatively predicted both drinking and number of sexual partners. Furthermore, closeness was not directly related to any outcomes, but appeared to act as a moderator in that when maternal closeness was high, then high levels of maternal knowledge were related to lower alcohol and drug use. We will discuss each of these findings in turn.

\section{Parental Knowledge and Child Outcomes}

Not only do parents claim to have knowledge about what their emerging-adult children are doing, it appears that this perceived knowledge is related to aspects of their children's behavior. Parental knowledge was linked to several positive outcomes for emerging-adult children, even after controlling for parental closeness. Again, alcohol use, drug use, and risky sexual behavior all appeared to decrease in the presence of parental knowledge for both young men and young women. These results suggest that young people may perceive parental knowledge as an indication that their parents are engaged in the relationship and, therefore, may view parental knowledge positively. As a result, parental knowledge may serve as a protective factor amidst the instability of emerging adulthood. Findings in earlier stages of development (e.g., middle childhood, adolescence) suggest that parental knowledge is a factor that is connected to positive development, especially for boys (see Crouter and Head 2002 for a review). These findings provide evidence that in emerging adulthood parental knowledge may help both young women and young men. While acknowledging that the direction of effects in this relation cannot be determined via the correlational design of this study, it is possible that the more that parents know about their sons' and daughters' behavior, the less likely those children are to engage in risk behaviors such as drug and alcohol use, as well as risky sexual behaviors. Given the bidirectional nature of the parent-child relationship, it is also possible that emerging adults who engage in fewer risk behaviors are more likely to disclose to parents, and perhaps emerging adults with high risk behaviors intentionally withhold information from their parents. That being said, the results of the current study add meaningfully to our understanding of the protective role that parental knowledge plays by extending into emerging adulthood the linkages between parental knowledge and positive outcomes.

\section{Closeness as a Moderator of Parental Knowledge} and Child Risk Behaviors

A key contribution of this study is the finding that parental knowledge is important in its association with risk behaviors in emerging adulthood above and beyond the influence of parental closeness. However, our findings also support 
the theoretical notion that the emotional climate of the parent-child relationship (Darling and Steinberg 1993) may be an important factor in how the child interprets parental behavior. Specifically, the findings between selfreported maternal knowledge and less alcohol and drug use were strongest when maternal closeness was high. As noted previously, Nelson and colleagues (in press) have found that parents are concerned about their children's drug and alcohol use in the process of becoming an adult. As a result, parents may attempt to monitor the extent to which their children engage in risk behaviors. Whether or not this monitoring is seen as intrusive may depend on the quality of the parent-child relationship. Indeed, parents, especially mothers, who are able to maintain a warm, close relationship with their children may be able to monitor their children's behavior in these areas without being perceived as controlling or intrusive. In fact, a close relationship may enable young people to interpret their mothers' solicitation of information as concern, which leads to less participation with drugs and alcohol. Again, these explanations are purely speculative given the inability to draw causal conclusions from correlational data. Nevertheless, the findings provide important evidence that the parent-child relationship continues to be of importance in the lives of children well into emerging adulthood by showing that parental knowledge in the context of a close mother-child relationship was importantly related to both young men's and young women's participation in risk behaviors.

\section{Differences Between Child- and Parent-reported Parental Knowledge}

It is worth noting the different results that emerged based on whether parental knowledge was assessed via child- or parent-report. Research on adolescents finds relative consistency between child- and parent-reported parental knowledge as they are related to child outcomes (e.g., Kerr and Stattin 2000). Despite emphasizing the importance of examining both parent and child reports of parenting and much debate about whose perceptions are more accurate or meaningful (Glasgow et al. 1997), research on parenting ultimately concludes that parent and child reports are typically only weakly correlated (Barker et al. 2007), necessitating the inclusion of multiple reporters whenever possible. The current study suggests that having multiple informants might be even more essential during emerging adulthood, as physical distance between parents and children may exacerbate already existing differences in perceptions. Although child- and parent-reported parental knowledge presented relatively different stories in the current study, they both highlighted the importance of parental knowledge during the transition to adulthood.
Paternal knowledge emerged as a direct predictor of outcomes only when assessed using child reports. In that case, paternal knowledge negatively predicted drug use and number of sexual partners. However, when considering parent-reported parental knowledge, paternal reports were unrelated to child outcomes. For a number of reasons, it may not be surprising that maternal knowledge was a stronger predictor than paternal knowledge. First, results showed that mothers had greater perceived knowledge of their children's activities than did fathers. This is consistent with findings in adolescence that mothers spend more time with their children and fathers know less about their children's activities (Crouter et al. 1999; Steinberg and Silk 2002), and thereby extends these results into emerging adulthood. Interestingly, however, it was child reports that were predictive for fathers, whereas all significant findings for mothers came via maternal assessments. This might suggest that when children perceived that their fathers knew about their activities, they were less likely to engage in drug use and risky sex, suggesting that perceived father involvement is also still important in the lives of young people during emerging adulthood. Whereas closeness did not moderate this relationship, it is unclear whether young people perceived their fathers' knowledge in a positive (e.g., appreciated their fathers' concern) or negative (e.g., feared their fathers' reactions) light. Future research should examine possible moderators of father knowledge (particularly as perceived from the child's point of view) and child outcomes in emerging adulthood as these results suggest that they are indeed related in a meaningful way in the lives of young people. Future research should also continue to examine both parent and child perceptions of parental knowledge, as they appear to be differentially related to child outcomes.

\section{Implications}

This study has several implications for young people's development during the period of emerging adulthood. First, research has shown that young people who are still transitioning to adulthood may be at risk for drug use (Nelson and Barry 2005) and risky sexual behavior (Lefkowitz and Gillen 2006). Thus, identifying parental knowledge as a possible protective factor against these outcomes during emerging adulthood (whether as a function of child disclosure or parental solicitation) is an important contribution to our understanding of how parents, educators, and clinicians might foster positive development during the transition to adulthood.

Second, the results of this study suggest important ramifications for our understanding of the parent-child relationship during this period of development. Emerging 
evidence suggests that parents may have different criteria for becoming an adult than do their children (Nelson et al., in press). Specifically, Nelson and colleagues found that parents place more emphasis than do their children (sons, especially) on the importance of complying with societal norms (i.e., avoiding becoming drunk, drunk driving, illegal drugs, committing petty crimes) to be considered an adult. Thus, if parents are concerned about their children being involved in these behaviors and if parents do not feel they have adequate knowledge of what their children are doing, parents may engage in higher levels of solicitation which, in turn, may be perceived as intrusive and overcontrolling. Future work is needed to examine causal mechanisms at work in this relationship as well as associated outcomes for the parent-child relationship.

Finally, given that parental knowledge is associated with positive aspects of emerging adulthood, it is important to clarify what other variables may moderate this relation. For example, child and relationship factors (e.g., perception of oneself as an adult or not, financial reliance on parents) may influence the link between parental knowledge and child externalizing behaviors as well as possibly internalizing problems, and positive adjustment (both areas deserving of future work). Given their salience for achieved adulthood status, emotional regulation and psychological maturity might also be important moderators of (or mediators between) parental knowledge and child outcomes. Indeed, a recent study found that emotional regulation and psychological maturity were mediators (especially for young women) between parenting and emerging-adult behavioral outcomes (Fischer et al. 2007). Moreover, there is a need to determine how parents gain their knowledge. Given past research showing that children who self-disclose typically engage in fewer problem behaviors (Stattin and Kerr 2000), the positive results for young people found in the current study would suggest that child self-disclosure was the primary source of parents' knowledge. However, given that the current study cannot determine that with certainty, future work is necessary to examine how various knowledge-gathering strategies are linked differentially to outcomes in emerging adulthood. Furthermore, given that parental knowledge is important in emerging adulthood, researchers may wish to examine what other aspects of parenting (e.g., beliefs, practices) continue to be important to children during emerging adulthood.

\section{Limitations and Conclusions}

As cited previously, the most notable limitation is the correlational nature of the study, which precludes causal inferences. Whereas we have speculated about possible causal processes throughout the discussion, the data precluded us from making conclusive statements. Second, our study included participants whose parents were willing to participate. It may be that a parent's willingness to participate (or the child's willingness to invite them to participate) may be a reflection of a better parent-child relationship. Thus, our sample may not reflect the full range of parent-child relationships and, therefore, may actually underestimate the relations between parental knowledge and risk behaviors. Another limitation of the study is that participants included only university students. Future work needs to include participants who are not attending college to determine whether parental knowledge also continues to play an important role for emerging adults who directly enter the work force or alternate educational and job training programs after high school. Next, although the sample drew from different types and sizes of universities throughout the country, the sample lacked ethnic and socioeconomic diversity. Given research suggesting that family ties are especially important for African-American and Hispanic youth (Coll and Pachter 2002), future work should examine these relations within a larger and more diverse population. Further, given the focus on family triads, the current study was unrepresentative of single-parent families, and future research should examine more diverse family types as well.

Finally, a small portion of this sample (10\%) included young people still living at home. It is possible that young people who live at home may differ in some meaningful way from those who do not (although that was not found in the current study). There is no extant evidence that these two groups differ in risk behaviors but there is some indication that young people living at home have poorer relationships with their parents than do their peers who live away from home (Dubas and Petersen 1996). However, it is not known whether this is due to the normal friction that living in the same household brings (Arnett 2004) or some other reasons possibly including tension over parental monitoring. Future work should examine differences based on the residence status of the emerging adult in areas such as closeness, parental knowledge and risk behaviors.

Despite these limitations, the study makes several significant contributions. The study provides one of the first examinations of the relations between perceived parental knowledge and risk behaviors in emerging adulthood. Specifically, results suggest that parental knowledge appears to be a protective factor, over and above parental closeness, but the emotional climate (i.e., closeness to mother) does indeed play an important role as well. Furthermore, both paternal and maternal knowledge were included in the study. Results show that parent gender matters in the linkages between parental knowledge and child outcomes, as does whether parental knowledge is 
assessed via the perceptions of parent or the child. Taken together, the study represents an important first step in understanding the roles that parents play in their children's development during the transition to adulthood.

Acknowledgements The authors express appreciation to the instructors and students at all Project READY data collection sites for their assistance. We also are grateful for the grant support of the Family Studies Center at Brigham Young University, as well as the junior faculty sabbatical grant given to the fourth author by Loyola College in Maryland.

\section{References}

Aiken, L. S., \& West, S. G. (1991). Multiple regression: Testing and interpreting interactions. Newbury Park: Sage.

Allen, J., \& McElhaney, K. (2000). Autonomy in discussion vs. autonomy in decision making as predictors of developing close friendship competence. Paper presented at the biennial meeting of the Society for Research on Adolescence, Chicago, IL.

Arnett, J. J. (2000). Emerging adulthood: A theory of development from the late teens through the twenties. American Psychologist, $55,469-480$.

Arnett, J. J. (2004). Emerging adulthood: The winding road from the late teens through the twenties. NY: Oxford Press.

Arnett, J. J. (2005). The developmental context of substance use in emerging adulthood. Journal of Drug Issues, 35, 235-253.

Arnett, J. J. (2006). Emerging adulthood: Understanding the new way of coming of age. In J. J. Arnett \& J. L. Tanner (Eds.), Emerging adults in America: Coming of age in the 21st century (pp. 3-20). Washington, D.C.: American Psychological Association.

Arnett, J. J. (2007). Suffering, selfish, slackers? Myths and reality about emerging adults. Journal of Youth and Adolescence, 36, 23-29.

Aquilino, W. S. (2006). Family relationships and support systems in emerging adulthood. In J. J. Arnett \& J. L. Tanner (Eds.), Emerging adults in America: Coming of age in the 21st century (pp. 193-218). Washington, D.C.: American Psychological Association.

Badger, S., Nelson, L. J., \& Barry, C. M. (2006). Perceptions of the transition to adulthood among Chinese and American emerging adults. International Journal of Behavioral Development, 30, 84-93.

Barber, B. K., Olsen, J. E., \& Shagle, S. C. (1994). Associations between parental psychological and behavioral control and youth internalized and externalized behaviors. Child Development, 65, $1120-1138$.

Barker, E. T., Bornstein, M. H., Putnick, D. L., Hendricks, C., \& Suwalsky, J. T. D. (2007). Adolescent-mother agreement about adolescent problem behaviors: Direction and predictors of disagreement. Journal of Youth and Adolescence, 36, 950-962.

Barnes, G. M., Hoffman, J. H., Welte, J. W., Farrell, M. P., \& Dintcheff, B. A. (2006). Effects of parental monitoring and peer deviance on substance use and delinquency. Journal of Marriage and Family, 68, 1084-1104.

Barry, C. M., Padilla-Walker, L. M., Madsen, S. D., \& Nelson, L. J. (in press). The impact of maternal relationship quality on emerging adults' prosocial tendencies: Indirect effects via regulation of prosocial values. Journal of Youth and Adolescence.

Bartle-Haring, S., Brucker, P., \& Hock, E. (2002). The impact of parental separation anxiety on identity development in late adolescence and early adulthood. Journal of Adolescent Research, 17, 439-450.
Bean, R. A., Barber, B. K., \& Crane, D. R. (2006). Parental support, behavioral control, and psychological control among African American youth: The relationships to academic grades, delinquency, and depression. Journal of Family Issues, 27, 13351355.

Buchanan, C. M., Maccoby, E. E., \& Dornbusch, S. M. (1991). Caught between parents: Adolescents' experience in divorced homes. Child Development, 62, 1008-1029.

Coll, C. G., \& Pachter, L. M. (2002). Ethnic and minority parenting. In M. H. Bornstein (Ed.), Handbook of parenting: Vol. 4: Social conditions and applied parenting (2nd ed., pp. 1-20). Mahwah, NJ: Lawrence Erlbaum Associates.

Côté, J. E. (2000). Arrested adulthood: The changing nature of maturity and identity. New York: New York University Press.

Crouter, A. C., \& Head, M. R. (2002). Parental monitoring and knowledge of children. In M. H. Bornstein (Ed.), Handbook of parenting: Vol. 3: Being and becoming a parent (2nd ed., pp. 461-484). Mahwah, NJ: Lawrence Erlbaum Associates.

Crouter, A. C., Helms-Erikson, H., Updegraff, K., \& McHale, S. M. (1999). Conditions underlying parents' knowledge about children's daily lives in middle childhood: Between- and withinfamily comparisons. Child Development, 70, 246-259.

Darling, N., \& Steinberg, L. (1993). Parenting style as a context: An integrative model. Psychological Bulletin, 113, 487-496.

Dishion, T. J., \& McMahon, R. J. (1998). Parental monitoring and the prevention of child and adolescent problem behavior: A conceptual and empirical formulation. Clinical Child and Family Psychology Review, 1, 61-75.

Dubas, J. S., \& Petersen, A. C. (1996). Geographical distance from parents and adjustment during adolescence and young adulthood. New Directions for Child Development, 71, 3-19.

Edwards, C. P., \& Liu, W. (2002). Parenting toddlers. In M. H. Bornstein (Ed.), Handbook of parenting: Vol. 1: Children and parenting (2nd ed., pp. 45-72). Mahwah, NJ: Lawrence Erlbaum Associates.

Feiring, C., \& Lewis, M. (1993). Do mothers know their teenagers' friends? Implications for individuation in early adolescence. Journal of Youth and Adolescence, 22, 337-354.

Fischer, J. L., Forthun, L. F., Pidcock, B. W., \& Dowd, D. A. (2007). Parent relationships, emotional regulation, psychosocial maturity, and college student alcohol use problems. Journal of Youth and Adolescence, 36, 912-926.

Glasgow, K. L., Dornbusch, S. M., Troyer, L., Steinberg, L., \& Ritter, P. L. (1997). Parenting styles, adolescents' attributions, and educational outcomes in nine heterogeneous high schools. Child Development, 68, 507-529.

Guo, J., Chung, I. J., Hill, K. G., Hawkins, J. D., Catalano, R. F., \& Abbott, R. D. (2002). Developmental relationships between adolescent substance use and risky sexual behavior in young adulthood. Journal of Adolescent Health, 31, 354-362.

Keniston, K. (1971). Youth and dissent: The rise of a new opposition. New York: Harcourt Brace Jovanovich.

Kenny, M. E., \& Sirin, S. R. (2006). Parental attachment, self-worth, and depressive symptoms among emerging adults. Journal of Counseling \& Development, 84, 61-71.

Kerr, M., \& Stattin, H. (2000). What parents know, how they know it, and several forms of adolescent adjustment: Further support for a reinterpretation of monitoring. Development Psychology, 36, 366-380.

Lefkowitz, E. S. (2005). “Things have gotten better:” Developmental changes among emerging adults after the transition to university. Journal of Adolescent Research, 20, 40-63.

Lefkowitz, E. S., \& Gillen, M. M. (2006). "Sex is just a normal part of life": Sexuality in emerging adulthood. Emerging adults in America: Coming of age in the 21st century (pp. 235-256). Washington, D.C.: American Psychological Association. 
Longmore, M. A., Manning, W. D., \& Giordano, P. C. (2001). Preadolescent parenting strategies and teens' dating and sexual initiation: A longitudinal analysis. Journal of Marriage and the Family, 63, 322-335.

Maccoby, E. E. (1992). The role of parents in the socialization of children: A historical overview. Developmental Psychology, 1006-1017.

Nelson, L. J., \& Barry, C. M. (2005). Distinguishing features of emerging adulthood: The role of self-classification as an adult. Journal of Adolescent Research, 20, 242-262.

Nelson, L. J., Padilla-Walker, L. M., Carroll, J. S., Madsen, S., Barry, C. M., \& Badger, S. (2007). 'If you want me to treat you like an adult, start acting like one!' Comparing the criteria for adulthood among emerging adults and their parents. Journal of Family Psychology, 21, 665-674.

O’Connor, T. G., Allen, J. P., Bell, K. L., \& Hauser, S. T. (1996). Adolescent-parent relationships and leaving home in young adulthood. New Directions for Child Development, 71, 39-52.

Pettit, G. S., Laird, R. E., Dodge, K. A., Bates, J. E., \& Criss, M. M. (2001). Antecedents and behavior-problem outcomes of parental monitoring and psychological control in early adolescence. Child Development, 72, 583-598.

Santelli, J. S., Brener, N. D., Lowry, R., Bhatt, A., \& Zabin, L. S. (1998). Multiple sexual partners among U.S. adolescents and young adults. Family Planning Perspectives, 30, 271-275.

Schulenberg, J. E., \& Zarrett, N. R. (2006). Mental health during emerging adulthood: Continuity and discontinuity in courses, causes, function. In J. J. Arnett \& J. L. Tanner (Eds.), Emerging adults in America: Coming of age in the 21st century (pp. 135172). Washington, D.C.: American Psychological Association.

Stattin, H., \& Kerr, M. (2000). Parental monitoring: A reinterpretation. Child Development, 71, 1072-1085.

Steinberg, L. (1990). Autonomy, conflict, and harmony in the family relationship. In S. Feldman \& G. Elliott (Eds.), At the threshold: The developing adolescent (pp. 255-276). Cambridge: Harvard University Press.

Steinberg, L. (2001). We know some things: Parent-adolescent relationships in retrospect and prospect. Journal of Research on Adolescence, 11, 1-19.

Steinberg, L., \& Silk, J. S. (2002). Parenting adolescents. In M. H. Bornstein (Ed.), Handbook of parenting: Vol. 1: Children and parenting (2nd ed., pp. 103-133). Mahwah, NJ: Lawrence Erlbaum Associates.

Strom, P. S., \& Strom, R. (2005). Parent-child relationships in early adulthood: College students living at home. Community College Journal of Research and Practice, 29, 517-529.

Tragesser, S. L., Beauvais, F., Swaim, R. C., Edwards, R. W., \& Oetting, E. R. (2007). Parental monitoring, peer drug involvement, and marijuana use across three ethnicities. Journal of Cross-Cultural Psychology, 38, 670-694.

Zarit, S. H., \& Eggebeen, D. J., (2002). Parent-child relationships in adulthood, later years. In M. H. Bornstein (Ed.), Handbook of parenting: Vol. 1: Children and parenting (2nd ed., pp. 135161). Mahwah, NJ: Lawrence Erlbaum Associates.

\section{Author Biographies}

Laura M. Padilla-Walker is an Assistant Professor in the School of Family Life at Brigham Young University. She received her Ph.D. from the University of Nebraska-Lincoln in 2005. Her major research interests center on the parent-child relationship as it relates to moral and prosocial behaviors during adolescence and emerging adulthood.

Larry J. Nelson is an Associate Professor in the School of Family Life at Brigham Young University. He received his Ph.D. in 2000 from the University of Maryland, College Park. His major research interests are in social and self development during early childhood and emerging adulthood.

Stephanie D. Madsen is an Associate Professor of Psychology at McDaniel College. She received her Ph.D. in 2001 from the Institute of Child Development, University of Minnesota. Her major research interests center on how relationships with significant others impact child and adolescent development.

Carolyn McNamara Barry is an Associate Professor of Psychology at Loyola College in Maryland. She received her Ph.D. in 2001 from the University of Maryland, College Park. Her major research interests are in social and self development during adolescence and emerging adulthood. 